\title{
HISTORIA ORGANÓW W KOŚCIELE NAJŚWIĘTSZEGO SERCA PANA JEZUSA W TARNOWIE
}

Kościół Najświętszego Serca Pana Jezusa w Tarnowie budowany był w dwóch etapach: w latach 1935-1939 oraz 1947-1952. Parafię erygowano w 1949 roku. Warto wspomnieć, iż pierwszy etap budowy kościoła prowadził z ramienia kurii diecezjalnej w Tarnowie ks. infułat Roman Sitko, beatyfikowany w 1999 roku przez papieża Jana Pawła $\mathrm{II}^{2}$.

Budynek kościoła został zaprojektowany przez architekta Konstantego Jakimowicza z Warszawy. Jest to typ bazyliki, z trzema nawami i transeptem. Wzdłuż naw bocznych znajduje się sześć kaplic, przy prezbiterium od strony wschodniej kaplica adoracji Najświętszego Sakramentu. Od strony południowej dwie wieże o identycznej wysokości. Utrzymany jest w stylu modernistycznym ${ }^{3}$.

Mimo że historia kościoła Serca Jezusowego obiektywnie nie jest długa, to organy, które są w chwili obecnej dla niego budowane, będą już trzecimi z kolei. Niniejszy artykuł ma na celu przedstawienie historii każdego z tych instrumentów.

\section{PIERWSZE ORGANY}

Kościół na Grabówce został wyposażony w organy piszczałkowe po II wojnie światowej. Na stronie internetowej parafii w zakładce Rys historyczny znajduje się notka o tym, że w 1949 roku do kościoła zakupione zostały małe organy ${ }^{4}$. Informacja ta jest, jak się wydaje, tylko w części prawdziwa. Prawdą jest, że zamontowano wtedy niewielkie organy, jednakże według dokumentów dostępnych w Archiwum

\footnotetext{
${ }^{1}$ Wojciech Szczerba, mgr sztuki, organista w kościele Najświętszego Serca Pana Jezusa w Tarnowie oraz nauczyciel w Diecezjalnej Szkole Organistowskiej w Tarnowie.

${ }^{2}$ P. Gajda, Parafia Najświętszego Serca Jezusowego, w: Encyklopedia Tarnowa, red. A. Niedojadło, Tarnów 2010, s. 300.

${ }^{3}$ Kościoły diecezji tarnowskiej, „Rocznik Diecezji Tarnowskiej” 1972, s. 518-519.

${ }^{4}$ C. Wryk, Z historii parafii Najświętszego Serca Pana Jezusa. Wspomnijmy na minione dni, http://www.nspj.diecezja.tarnow.pl/index.php/historia/rys-historyczny (12 VIII 2014).
} 
Diecezjalnym w Tarnowie organy te zostały dla parafii Serca Jezusowego wypożyczone, a nie zakupione ${ }^{5}$.

Przybliżymy zatem historię tego instrumentu. Z dostępnych źródeł wynika, że wspomniane organy zostały wybudowane przez firmę Ignacego i Aleksandra Żebrowskich ze Lwowa dla tamtejszego kościoła Sercanek (Sacré Coeur) w 1882 roku'. Posiadały one 12 głosów. Po drugiej wojnie światowej siostry musiały opuścić Lwów. Udało im się wtedy wywieźć do Polski organy, które znalazły się następnie w klasztorze w Zbylitowskiej Górze. Stamtąd zostały one wypożyczone do kościoła Najświętszego Serca Pana Jezusa w Tarnowie, gdzie grały do roku $1968^{7}$, kiedy to Tadeusz Rajkowski rozpoczynał pracę nad nowym instrumentem. Z kościoła na Grabówce organy trafiły do parafii Paszyn koło Nowego Sącza, gdzie zamontowali je Bronisław Kaltenbeck i Bronisław Narolski ${ }^{8}$. Właśnie z Paszyna pochodzą informacje na temat tego instrumentu, znajdujące się w Archiwum Diecezjalnym w Tarnowie. Według ankiety organowej sporządzonej w 1971 roku dyspozycja organów była następująca9

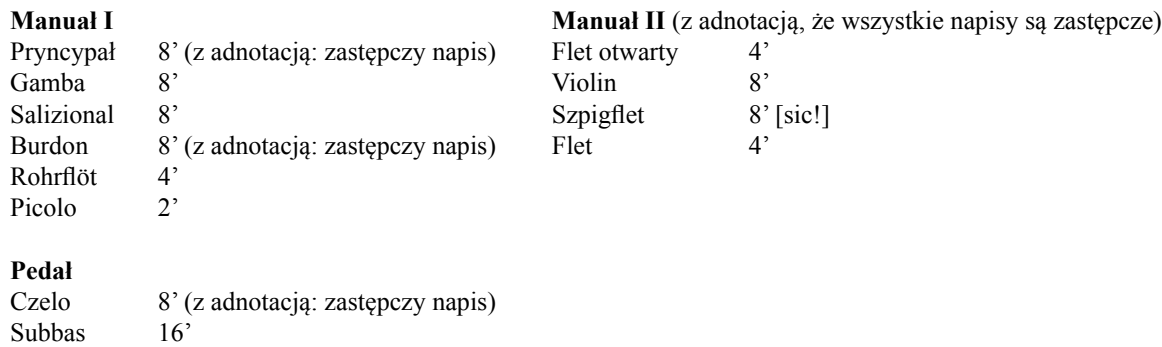

Instrument ten posiadał mechaniczną trakturę gry i wiatrownice klapowo-zasuwowe $^{10}$. Obecnie jest on nadal używany w parafii Paszyn ${ }^{11}$.

\section{ORGANY TADEUSZA RAJKOWSKIEGO}

Jak już wcześniej wspomniano, w latach sześćdziesiątych XX wieku firma Tadeusza Rajkowskiego z Włocławka rozpoczęła prace nad nowymi organami piszczałkowymi dla kościoła Najświętszego Serca Pana Jezusa w Tarnowie. Prawdopodobnie Rajkowski składał trzy oferty na wykonanie instrumentu dla tej parafii.

${ }^{5}$ Archiwum Diecezji Tarnowskiej, Ankieta dotyczaca organów [w Paszynie], teczka Akta rzeczowe Kurii Diecezjalnej w Tarnowie. Wydziat Muzyki Kościelnej. Ankieta dotyczaca organów, sygn. ARz 119; L.dz. 552/VI-1/3/71.

${ }^{6}$ M. Babnis, Kultura organowa Galicji, Słupsk 2012, s. 414.

${ }^{7}$ Archiwum Diecezji Tarnowskiej, Ankieta ..., dz. cyt.

${ }^{8}$ M. Babnis, Kultura ..., dz. cyt., s. 414.

${ }^{9}$ Archiwum Diecezji Tarnowskiej, Ankieta ..., dz. cyt.

10 Tamże.

${ }^{11}$ Według relacji ustnej P. Pasternaka. 
Zachowały się tylko dwie, ale o istnieniu jeszcze jednej świadczy fakt, że oferta z 1964 roku jest oznaczona numerem 2. Projekt ten nie został zrealizowany ${ }^{12}$. Warto wspomnieć, że miały to być organy 50-głosowe, o trakturze elektro-pneumatycznej. Projekt dyspozycji przedstawiał się następująco ${ }^{13}$ :

\begin{tabular}{|c|c|c|c|c|c|}
\hline \multicolumn{2}{|l|}{ Manual I } & \multicolumn{2}{|l|}{ Manual II } & \multicolumn{2}{|l|}{ Manual III } \\
\hline Bourdon & $16^{\prime}$ & Kryty pomorski & 8 ' & Kwintadena & 8 \\
\hline Pryncypał & $8^{\prime}$ & Pryncypał flet & 8, & Prync. skrzypcowy & 8 \\
\hline Flet jasny & $8^{\prime}$ & Flet otwarty & 8, & Viola gamba & 8, \\
\hline Gemshorn & $8^{\prime}$ & Salicet & 8 ' & Unda maris & 8 \\
\hline Oktawa & $4^{\prime}$ & Pryncypał włoski & $4^{\prime}$ & Pryncyp. włoski & $4^{\prime}$ \\
\hline Flet leśny & $4^{\prime}$ & Rurflet & $4^{\prime}$ & Flet śpiewny & $4^{\prime}$ \\
\hline Flet koniczny & $2^{\prime}$ & Nasard & $2 \frac{2}{3}$, & Dubeltflet & $4^{\prime}$ \\
\hline Kwinta & $2 \frac{2}{3}$ & Dublet & 2 & Blcflet [sic!] & 2 ' \\
\hline Mixtura & $4 \mathrm{ch}$ & Picolo & 1 ' & Róg nocny & 2 ' \\
\hline Trompet & $8^{\prime}$ & Kornet & $4 \mathrm{ch}$ & Kwi[n]ta śpiewna & $1 \frac{1}{3}$, \\
\hline & & Klarnet & $8^{\prime}$ & Tercflet & $13 / 5$ \\
\hline & & Siflet & 1 ' & & \\
\hline & & Cymbel & $3 \mathrm{ch}$ & & \\
\hline & & Vox humana & 8, & & \\
\hline & & Pryncypał serafon & 8, & & \\
\hline & & Flet podwójny serafon & 8 ' & & \\
\hline & & Rurflet serafon & $4{ }^{\prime}$ & & \\
\hline & & Róg serafon & 2 & & \\
\hline
\end{tabular}

$\begin{array}{ll}\text { Pedal } & \\ \text { Pryncypałbas } & 16 \\ \text { Violon } & 16 \\ \text { Echobas } & 16, \\ \text { Oktawbas } & 8, \\ \text { Salicet } & 8, \\ \text { Fletbas } & 8, \\ \text { Chorał } & 4, \\ \text { Kwinta } & 51 / 3, \\ \text { Róg } & 2 \\ \text { Mixtura } & 3 \mathrm{ch} \\ \text { Puzon } & 16\end{array}$

Ciekawostką tego projektu były tzw. serafony, czyli głosy grające na wyższym ciśnieniu. Rajkowski przewidywał dla nich ciśnienie powietrza o wysokości 200 mm słupa wody, osobną obudowę oraz miech ${ }^{14}$.

W 1967 roku firma Rajkowskiego przedstawiła kolejny kosztorys na jeszcze większe organy. Miały posiadać 71 głosów, rozdzielonych pomiędzy cztery manuały i pedał. Dyspozycję instrumentu zaprojektował prof. Jan Jargoń z Krakowa ${ }^{15}$. Zanim

${ }^{12}$ P. Pasternak, Działalność organmistrzowska Tadeusza Rajkowskiego, Warszawa 2014 (mps pracy licencjackiej), s. 52.

${ }^{13}$ Tamże, s. 52-53; Archiwum Tadeusza Rajkowskiego, Kosztorys 2 na organy dla kościoła parafialnego Tarnów-Grabówka ul. Lwowska 110 z 1 grudnia 1964, dokument udostępniony przez P. Pasternaka.

${ }^{14}$ Archiwum Tadeusza Rajkowskiego, Kosztorys 2..., dz. cyt.

${ }^{15}$ Archiwum Tadeusza Rajkowskiego, Ulotka reklamowa o organach w kościele NSPJ w Tarnowie, dokument udostępniony przez P. Pasternaka. 
rozpoczęły się prace przy budowie nowych organów, na chórze została wmurowana marmurowa tablica z napisem: „Kamień węgielny pod budowę organu w kościele N. Serca Jezusowego w Tarnowie fundowanego przez parafian na pamiątkę tysiąclecia chrztu Polski”. Znajduje się tam ona do dnia dzisiejszego.

Jak już zostało wspomniane, oferta Rajkowskiego została przedstawiona w 1967 roku, natomiast prace miały trwać od roku następnego do listopada roku $1969^{16}$. Tak się jednak nie stało. Prawdopodobnie z przyczyn zdrowotnych Tadeusz Rajkowski nie był w stanie wywiązać się z terminu, a instrument został ukończony dopiero w roku 1972. Dyspozycja organów była następująca ${ }^{17}$ :

$\begin{array}{ll}\text { Manual I } & \\ \text { Flet kryty } & 8 \\ \text { Kwintadena } & 8 \\ \text { Musette } & 8, \\ \text { Pryncypał } & 4 \\ \text { Blokflet } & 4 \\ \text { Szałamaja } & 4, \\ \text { Oktawa } & 2, \\ \text { Kwinta mała } & 1 \frac{1}{3}, \\ \text { Sesquialtera } & 2 \mathrm{ch} . \\ \text { Acuta } & 4 \mathrm{ch} .\end{array}$

$\begin{array}{ll}\text { Manual II } & \\ \text { Pryncypał } & 16 \\ \text { Trompet } & 16, \\ \text { Oktawa } & 8^{\prime} \\ \text { Flet otwarty } & 8^{\prime} \\ \text { Bourdon } & 8^{\prime} \\ \text { Gamba } & 8^{\prime} \\ \text { Trompet } & 8^{\prime} \\ \text { Nasard wielki } & 5 \frac{1}{3}, \\ \text { Oktawa } & 4, \\ \text { Flet stożkowy } & 4 \\ \text { Kwinta } & 2 \frac{2}{3}, \\ \text { Superoktawa } & 2 ' \\ \text { Flautino } & 2, \\ \text { Mixtura major } & 6 \mathrm{ch} . \\ \text { Mixtura minor } & 4 \mathrm{ch} . \\ \text { Kornet } & 4 \mathrm{ch} .\end{array}$

\begin{tabular}{|c|c|}
\hline \multicolumn{2}{|l|}{ Manual III } \\
\hline Kwintadena & $16^{\prime}$ \\
\hline Fagot & $16^{\prime}$ \\
\hline Pryncypał & 8 \\
\hline Rurflet & $8^{\prime}$ \\
\hline Salicjonał & 8 \\
\hline Vox coelestis & 8, \\
\hline Obój & 8 \\
\hline Prestant & 4 \\
\hline Róg nocny & $4^{\prime}$ \\
\hline Clajron & $4^{\prime}[\mathrm{sic} !]$ \\
\hline Nasard & $2 \frac{2}{3}$ \\
\hline Oktawa & 2 ' \\
\hline Flet leśny & 2 ' \\
\hline Tercja & $13 / 5^{\prime}$ \\
\hline Picolo & 1 \\
\hline Mixtura & $4 \mathrm{ch}$. \\
\hline Terccymbel & $3 \mathrm{ch}$. \\
\hline
\end{tabular}

$\begin{array}{ll}\text { Manual IV } & \\ \text { Sordun } & 16 \\ \text { Flet drewniany } & 8 \\ \text { Vox Humana } & 8 \\ \text { Rurflet } & 4, \\ \text { Dulcjana } & 4 \\ \text { Pryncypał } & 2 \\ \text { Flageolet } & 1, \\ \text { Cymbel } & 4 \mathrm{ch} .\end{array}$

Pedal

Subkontra 32'

Pryncypał 16'

Violon 16,

Subbas 16'

Salicetbas $16^{\prime}$

Puzon 16'

Sordun $16^{\prime}$ (transmisja z manuału IV)

Oktawbas 8 '

Gemshorn 8'

Fletbas $\quad 8$,

Bombard $\quad 8$,

Musette $\quad 8^{\prime}$ (transmisja z manuału I)

Oktawa 4,

Dolcan 4'

Clarino 4

Flet polny 2'

Mixtura $5 \mathrm{ch}$.

Basalikwoty $4 \mathrm{ch}$.

Traktura gry i rejestrów była elektro-pneumatyczna, zakres klawiatur od $\mathrm{C}$ do $\mathrm{c}^{4}$ w manuałach oraz od $\mathrm{C}$ do $\mathrm{g}^{1} \mathrm{w}$ pedale. Organy zostały wyposażone w połączenia:

\footnotetext{
16 Tamże.

${ }^{17}$ P. Pasternak, Działalność ..., dz. cyt., s. 53-55; relacja ustna P. Pasternaka
} 
M II do M I; M III do M I; M IV do M I; M I do M II; M III do M II; M IV do M II; M IV do M III; M I do pedału; M II do pedału; M III do pedału; M IV do pedału; a także urządzenia dodatkowe: automat pedałowy; 6 wolnych kombinacji; crescendo; żaluzja manuału III; tremolo manuału I; tremolo manuału III; tremolo manuału IV; tremolo niektórych głosów pedału (Gemshorn 8', Fletbas 8', Oktawa 4', Dolcan 4', Bombard 8'); generalny wyłącznik głosów językowych; wyłączniki indywidualne głosów językowych; register zbiorowy Tutti ${ }^{18}$.

Były to jedne $\mathrm{z}$ największych organów w całym regionie i największe w diecezji tarnowskiej. Niestety instrument nie wytrzymał próby czasu. Ostatni generalny remont został przeprowadzony w 1992 roku przez firmę Rajkowskiego ${ }^{19}$. W tym też roku zakład ten zaprzestał działalności. Od ostatniego remontu stan organów systematycznie się pogarszał, nie podejmowano się remontu generalnego, a usterki były naprawiane jedynie w sposób doraźny. Już około 15 lat po remoncie generalnym w organach działało tylko kilkanaście głosów. Nie działały także niektóre klawisze.

W 2007 roku proboszczem parafii Najświętszego Serca Pana Jezusa w Tarnowie został ks. prałat Antoni Bielak. Niemal od razu musiał stanąć przed trudnym zadaniem rozstrzygnięcia kwestii organów. Pod uwagę brano kilka opcji: remont instrumentu, jego przebudowę z zachowaniem większości głosów z organów Rajkowskiego, a także całkowity demontaż organów i wybudowanie zupełnie nowych.

W lutym 2009 roku została przeprowadzona wstępna ekspertyza instrumentu. Brali w niej udział organmistrz Mirosław Jakubowski oraz ks. dr Grzegorz Piekarz, dyrektor Wydziału Muzyki Kościelnej Kurii Diecezjalnej w Tarnowie. Wyciągnięto wówczas następujące wnioski:

- instrument nie nadaje się do dalszego użytkowania i renowacji;

- jest możliwość przebudowy organów z wykorzystaniem głosów Rajkowskiego, jednakże tylko będących w dobrym stanie;

- poproszono o konsultację jeszcze jednego organmistrza - Andrzeja Ragana ${ }^{20}$.

W marcu 2009 roku ks. proboszcz Antoni Bielak poprosił ks. Grzegorza Piekarza o wygłoszenie słowa do parafian podczas wszystkich mszy niedzielnych. W słowie tym ks. Piekarz przedstawił wiernym stan organów Rajkowskiego, a także możliwości rozwiązania kwestii tego instrumentu, przy czym w słowie tym wyraźnie opowiadał się za przebudową organów z wykorzystaniem starych głosów ${ }^{21}$. Ostatecznie zdecydowano jednak inaczej. Według relacji ustnej niektórych członków ówczesnej Rady Duszpasterskiej przy parafii NSPJ, po przedstawieniu przez firmę organmistrzowską kosztów takiej przebudowy, zarówno proboszcz, jak i radni skłaniali się

${ }^{18}$ Tamże, s. 55.

${ }^{19}$ Relacja ustna S. Witka, organisty kościoła NSPJ w Tarnowie.

${ }^{20}$ Archiwum Wydziału Muzyki Kościelnej Kurii Diecezjalnej w Tarnowie, teczka Organy w par. NSPJ w Tarnowie. Dokumentacja, dokument Ekspertyza wstępna, bez sygn. Autor nie dotarł do materiałów, które dokumentują opinię organmistrza A. Ragana.

${ }^{21}$ Stowo do parafian NSPJ $w$ Tarnowie (8 III 2009), dokument ze zbiorów prywatnych ks. G. Piekarza. 
ku wybudowaniu zupełnie nowego instrumentu. Decyzja zapadła prawdopodobnie w $2009 \mathrm{roku}^{22}$. W tym samym roku organy zostały zdemontowane przez firmę Mirosława Jakubowskiego z Włocławka. Z całego instrumentu w dobrym stanie zachowały się jedynie piszczałki, które zostały przeznaczone na sprzedaż przez parafię.

\section{NOWE ORGANY}

W kwietniu 2010 roku w budynku plebanii parafii Najświętszego Serca Pana Jezusa obradowała podkomisja ds. budownictwa organowego diecezji tarnowskiej. W obradach wzięli udział: ówczesny proboszcz parafii ks. prał. Antoni Bielak, ks. dr Grzegorz Piekarz - dyrektor Wydziału Muzyki Kościelnej Kurii Diecezjalnej w Tarnowie, ks. mgr lic. Stefan Król - przewodniczący podkomisji; ks. prał. Tadeusz Bukowski - historyk sztuki, członek podkomisji; Kazimierz Plewa - organmistrz; Stanisław Wolak - organmistrz; mgr Krzysztof Siewkowski - niezależny doradca. Celem obrad było wyłonienie firmy, która miała wybudować nowe organy ${ }^{23}$. Spośród pięciu firm, które złożyły ofertę na wybudowanie nowego instrumentu, do dalszych rozmów postanowiono zaprosić trzy z nich: firmę Dariusza Zycha z Wołomina, czeską firmę Rieger-Kloss Varhany z Krnova oraz firmę Mirosława Jakubowskiego z Włocławka. Odrzucono ofertę Zdzisława Mollina z Odr, a także Jacka Siedlara z Modlnicy. Ustalono także, że dyspozycja będzie organmistrzom narzucona, nawiązująca stylistycznie do XIX-wiecznego symfonizmu we francuskim budownictwie organowym ${ }^{24}$. Autorem dyspozycji jest Krzysztof Siewkowski.

Już po kilku dniach, 15 i 16 kwietnia komisja spotkała się z przedstawicielami wszystkich trzech wyłonionych wcześniej firm: 15 kwietnia z przedstawicielem firmy Rieger-Kloss, natomiast 16 kwietnia z Dariuszem Zychem oraz Mirosławem Jakubowskim. Po analizie ofert oraz przedyskutowaniu ich z przedstawicielami firm komisja zaproponowała, by prace nad nowym instrumentem powierzyć firmie Dariusza Zycha lub firmie Rieger-Kloss ${ }^{25}$. Ostatecznie budowa nowych organów została zlecona firmie Zych z Wołomina, na co wpływ miały głównie znaczne różnice w kosztach budowy przedstawionych przez obydwie wyłonione firmy.

Jak już wspomniano, organy w kościele Najświętszego Serca Pana Jezusa w Tarnowie budowane były według założeń XIX-wiecznego symfonizmu francuskiego.

${ }^{22} \mathrm{~W}$ archiwum parafii nie ma dokumentu, który mówiłby jednoznacznie o dacie podjęcia ostatecznej decyzji. Można jednak przypuszczać, że był to rok 2009 (po słowie ks. Piekarza do parafian, a przed demontażem starych organów).

${ }^{23}$ Archiwum Wydziału Muzyki Kościelnej Kurii Diecezjalnej w Tarnowie, teczka Organy w par. NSPJ w Tarnowie. Dokumentacja, dokument Protokót ze spotkania Podkomisji ds. budownictwa sakralnego Diecezji Tarnowskiej z 9 kwietnia 2010, bez sygn.

${ }^{24}$ Tamże.

${ }^{25}$ Archiwum Wydziału Muzyki Kościelnej Kurii Diecezjalnej w Tarnowie, teczka Organy..., dokument Protokót ze spotkania Podkomisji ds. budownictwa sakralnego Diecezji Tarnowskiej z 15 i 16 kwietnia 2010, bez sygn. 
Chodzi tu głównie o warstwę brzmieniową instrumentu, a także wygląd zewnętrzny (np. kontuar) i nazewnictwo. Do tradycji francuskich nawiązuje także rozmieszczenie poszczególnych sekcji brzmieniowych oraz układ zasilania powietrzem. Od strony technicznej stosowane były współczesne podzespoły.

Dyspozycja nawiązuje bezpośrednio do francuskich organów romantycznych: przewaga głosów ośmiostopowych, kilka głosów szesnastostopowych, bateria głosów językowych etc. Także konstrukcja piszczałek (np. głosy językowe z tzw. orzechem, kilka głosów z piszczałkami przedętymi) i przebiegi menzur mają w jak największym stopniu oddać jakość brzmienia organów francuskich.

Dyspozycja organów:

$\begin{array}{lr}\text { Manual I - Grand Orgue } \\ \text { Montre } & 16, \\ \text { Montre } & 8, \\ \text { Flûte harmonique } & 8, \\ \text { Gambe } & 8, \\ \text { Bourdon } & 8, \\ \text { Prestant } & 4, \\ \text { Doublette } & 2 \\ \text { Cornet (od f) } & 5 \times \\ \text { Fourniture } & 5 \times \\ \text { Trompete } & 8 \\ \text { Clairon } & 4,\end{array}$

$\begin{array}{ll}\text { Manual II - Positif } & \\ \text { Bourdon } & 16, \\ \text { Montre } & 8, \\ \text { Salicjonal } & 8, \\ \text { Flûte à cheminée } & 8, \\ \text { Prestant } & 4, \\ \text { Flûte douce } & 4, \\ \text { Nasard } & 2 \frac{2}{3}, \\ \text { Quarte de nasard } & 2 \\ \text { Tierce } & 13 / 5, \\ \text { Plein jeu } & 4 \times \\ \text { Cromorne } & 8,\end{array}$

$\begin{array}{lc}\text { Manual III - Recit expressif } \\ \text { Flûte traversière } & 8^{\prime}, \\ \text { Cor de nuit } & 8^{\prime}, \\ \text { Viole de gamba } & 8^{\prime}, \\ \text { Voix celeste } & 8^{\prime}, \\ \text { Flute octaviante } & 4{ }^{2}, \\ \text { Nasard harmonique } & 2^{\prime}, \\ \text { Octavin } & 2^{\prime} \\ \text { Plein jeu harmonique } & 3 \times-6 \times \\ \text { Cornet (od f) } & 5 \times \\ \text { Bombarde } & 16^{\prime} \\ \text { Trompete harmonique } & 8^{\prime}, \\ \text { Hautbois } & 8^{\prime}, \\ \text { Voix humaine } & 8^{\prime}, \\ \text { Clairon harmonique } & 4,\end{array}$

Pedal

$\begin{array}{ll}\text { Soubasse } & 32, \\ \text { Flûte } & 16, \\ \text { Soubasse } & 16, \\ \text { Flûte } & 8^{\prime}, \\ \text { Violoncelle } & 8^{\prime}, \\ \text { Flûte } & 4, \\ \text { Bombarde } & 16, \\ \text { Trompete } & 8, \\ \text { Clairon } & 4,\end{array}$

Zakres klawiatur ręcznych to pełne pięć oktaw $\left(\mathrm{C}-\mathrm{c}^{4}\right)$, zaś klawiatury nożnej $\mathrm{C}-\mathrm{c}^{1}$. Traktura gry jest mechaniczna $\mathrm{z}$ zastosowanym wspomaganiem, natomiast traktura rejestrowa jest elektryczna. Takie rozwiązanie dało możliwość zainstalowania systemu „setzer”, dzięki któremu w pamięci komputera można zapisać 4 tysiące wolnych kombinacji.

Organy są wyposażone w połączenia pomiędzy poszczególnymi sekcjami oraz połączenia Sub w obrębie pojedynczych sekcji: Sub III; Sub III-II; III-II; Sub I; II-I; Sub III-I, III-I; Super III-I. Połączenia te obsługiwane są elektrycznie, za pomocą styków optycznych w kontuarze i elektromagnesów wprawiających abstrakty w ruch. Tylko połączenie manuału I do pedału jest realizowane mechanicznie.

Sekcja manuału III jest umieszczona w szafie ekspresyjnej. Dla II i III manuału przewidziano tremolo. W organach zainstalowano także crescendo, które można 
zaprogramować niezależnie na dwa różne sposoby. Obsługiwane jest przy pomocy wałka nożnego umieszczonego w kontuarze. Spośród urządzeń dodatkowych należy jeszcze wymienić generalny wyłącznik głosów języczkowych oraz register zbiorowy Tutti. Obydwa te urządzenia są obsługiwane za pomocą pistonów nożnych.

W chwili pisania tego artykułu zainstalowane i uruchomione są 24 głosy labialne w sekcjach pedału, manuału I oraz manuału III, a także jeden głos językowy (Bombarde 16') w pedale. W niedalekiej przyszłości planowane jest całkowite ukończenie budowy organów. Na koniec trzeba też powiedzieć, że będzie to jeden z nielicznych tego typu instrumentów w całej Polsce.

\section{SŁOWA KLUCZOWE}

organy, kościół Najświętszego Serca, Tarnów, Grabówka, historia, rejestracja

\section{SUMMARY}

\section{History of organ in the church of the Sacred Heart of Jesus in Tarnow}

The purpose of this article is to enunciate the history of the organs in the church of the Sacred Heart of Jesus in Tarnów - Grabówka. This church, which was being built from 1935 till 1939 and from 1945 till 1952, despite of its short history, had been a place for two instruments and now the third one is being built. The author of this article, basing on the available archives and oral reports, wrote the short history of all three instruments, showing their specification: disposition, technical information, etc.

\section{KEYWORDS}

organ, church of Sacred Heart, Tarnów, Grabówka, history, disposition 